https://doi.org/10.48009/2_iis_2007_171-179

\title{
ICT USE: THE INFLUENCE OF CULTURAL DIMENSIONS ON THE NEED FOR MEDIA RICHNESS AND TECHNOLOGICAL RICHNESS
}

\author{
Abdou Illia, Eastern Illinois University, aillia@eiu.edu \\ Assion Lawson-Body, University of North Dakota, assion_lawsonbody@und.nodak.edu
}

\begin{abstract}
Globalization is one of the major forces behind the growing need to know the extent to which culture and context-related variables influence information technology (IT) use. In this study, data collected from Chinese and Canadian managers was used to assess the impact of cultural dimensions on the extent to which people are interested in both media richness and technological features associated with Information and Communication Technologies (ICT). The results showed that there is a significant difference between Canadian and Chinese managers in terms of their interest in media richness. The results also showed that there is no relationship between cultural dimensions and peoples' interest in technological features like storage capacity, data accessibility, and ability to access messages anytime, anywhere.
\end{abstract}

Keywords: Culture, ICT, Media richness, Global Information Systems, IT adoption

\section{INTRODUCTION}

According to the Technology Acceptance Model (TAM), which is based on the theory of reasoned action (TRA), the actual use of an Information Technology (IT) is determined by beliefs a user holds about its perceived usefulness and its perceived ease of use (Davis [7]). An aspect of the TRA not taken into account by the TAM is that the actual use of a tool (e.g. an IT) is also determined by normative beliefs (e.g., culture). But what are the cultural dimensions that would, more likely, influence IT use by individuals? This issue is addressed next. Furthermore, the innovation diffusion theory applied at individual level by Rogers [36] states that characteristics inherent in technologies also influence IT use. Along this line, many studies performed in North America seem to show that IT characteristics like media richness and other IT features are important factors to take into account in order to gain a better understanding of IT use by individuals (Lippert \& Forman [29], El-Shinnawy \& Markus [9]). But according to Hall [18], the importance given to media richness criteria like the capacity to convey cues may vary across cultures. In short, as the TAM stated, IT use is basically a matter of perception (perceived usefulness, perceived ease of use). But as the innovation diffusion theory (Rogers [36]) and Hall [18] suggested, in this study we also consider that cultural dimensions and subjective appreciation of IT characteristics play a key role in explaining IT use. Therefore, the main objective of this study is to further our understanding of the influence of cultural dimensions and subjective appreciation of IT characteristics on our actual use of information technologies, in particular information and communication technologies (ICT). Unlike many previous studies on the subject, the main focus of this study is not to determine what specific transmission media are more likely to be adopted and used in different cultures. Instead, the focus of this study is to determine what features or what characteristics of transmission media are more likely to be needed in different cultures. More specifically, this study will try to answer two questions. First, what specific cultural dimensions (if any) are more likely to influence managers' preferences for ICT's characteristics like media richness (instant feedback, capacity to convey cues, personal focus, language variety), and technological richness (storage capacity, messages accessibility, 24-hour a day availability)? Secondly, is there a difference between Western culturally oriented managers (who have been the main target of most studies on IT use) and managers with different cultural background in terms of what ICT characteristics they prefer

\section{CULTURE AND IT USE}

Culture is a system of knowledge, of learned standards of perceiving, believing, evaluating and acting that are formed during childhood and reinforced throughout life (Viega et al. [46], Shore \& Vankatachalam [38]). This implies that culture has a strong influence on all our undertakings including the way we make decisions about using IT (Hasan \& Ditsa [19]). A variety of frameworks for assessing cultural dimensions have been suggested by Hall [18], Hofstede [24]), and Herbig [21] among others. For the purpose of our study, we have examined the literature on culture and IT use in order to identify dimensions and determinants of culture that could be relevant to IT use by people. As a result of this 
examination, we have identified two categories of cultural dimensions: those that are relevant to IT adoption by institutions like organizations or countries (macro level), and those that are more relevant to IT use by individuals (micro level). Since one of the main objective of this study is to investigate the cultural dimensions that influence people's preferences for ICT features (the micro level), in the remaining part of this paper we will focus on the following cultural dimensions that seem to be relevant to IT use by individuals: cultural context (Hall [18]), power distance, uncertainty avoidance, and collectivism (Hofstede [24]).

According to Hall [18], a society can be characterized as a high-context society or a low-context society based on the way communication takes place among its members. In low-context societies, people need to explicitly express in words all the information they have to transmit to others. In high-context societies, on the other hand, education and the context in which communication takes place allow people to understand each other with a minimum words being exchanged. Teboul et al [44] raised the question whether or not people could communicate effectively using non-visual communication technologies in high-context cultures. Along this line, Hasan \& Ditsa [19] showed that in high-context societies people tend to prefer using the face-to-face medium or new ICT with a high capacity for restoring the communications' context (e.g. videoconferencing) instead of lean communication media like email.

Power Distance refers to the extent to which the members of a society accept that the power is distributed unequally (Hofstede [24]). High power distance is associated to top-down decision-making and rigid hierarchical structure (Limaye [28]). According to Suh [43], new communication media like email have the capacity to break down hierarchical barriers by allowing employees to communicate directly with someone several levels higher on the organizational chart. With more traditional forms of communication, office staff would intercept the phone calls or the written messages (Filipczak [12]). This means that managers with high power distance would be less in favor of electronic media because of their potential to fatten hierarchies.

Uncertainty Avoidance refers to the extent to which members of a society feel uncomfortable with uncertainty (Hofstede [24]). High uncertainty avoidance leads to explicit (written) rules and regulations, and reliance to information systems. In high uncertainty avoidance cultures, people would be less willing to adopt IT-based innovations (Rogers
[36]). Along this line, Straub [39] tried to show that Japanese's high uncertainty avoidance is a key factor for explaining why Japanese prefer using traditional media (like fax) than new ICT like email.

According to Hasan \& Ditsa [19], collectivism goes with supportive work environment and group responsibility. Ho et al [22] tried to show that people with collectivist values would express less willingness to use electronic communication media because they allow less group interactions compared to the face-to-face medium. Furthermore, according to Straub, Keil \& Brenner [40] compared to the faceto-face medium, new electronic media have less capacity for exchanging social cues, which would make them less useful in collectivist societies.

\section{MEDIA RICHNESS, TECHNOLOGICAL RICHNESS, AND IT USE}

The media richness theory (MRT) as initially formulated by Daft \& Lengel ([2], [4]) proposes a hierarchy among communication media and suggests that there will be an optimal fit between the type of communication needed by managers and the type of communication media to choose. According to the MRT, communication media are characterized by the level of richness in communication they can provide based on four criteria: (1) the opportunity for instant feedback, (2) the ability to convey multiple cues, (3) the tailoring of messages to people and circumstances, and (4) the language variety permitted when communicating with the media. Based on these criteria, some communication media such as the faceto-face medium are supposed to be rich and others are supposed to be poor. At the same time, according to the proponents of the MRT, performance improves when managers use richer communication media for equivocal tasks (where there are multiple and possibly conflicting interpretations for the available information) and leaner communication media for non-equivocal tasks (Daft \& Lengel [2], [4]). Fulk et al [13] tried to integrate new ICT such as email in the MRT hierarchy and concluded that new ICT are less rich than traditional media. But other studies showed that, compared to traditional media, new ICT provide some form of richness not taken into account by the MRT like simultaneous use of video, audio, graphics, and text; capacity for accessing and retrieving saved messages and data; 24-hour a day availability; and synchronousness (Culnan \& Markus [1], Rice [35]). In this study, the concept technological richness is used to refer to that new kind of richness discovered with the growth of new ICT. 


\section{HYPOTHESES}

The proponents of the MRT assume that the theory's principles apply to all users whatever the context or environment. But according to authors like Hall [18], the importance given to media richness' criteria like the capacity to convey cues varies across cultures. In particular, in high-context cultures (for instance in China), people will need more cues and more instant feedback in communication than in Western countries where the cultural context is lower (Hall [18]). Along this line, we argue that media richness can help deal with ambiguity and uncertainty. This suggests that the higher the uncertainty avoidance on the one hand, the higher the need for cues, for instant feedback, for personal focus, and for language variety on the other hand. Therefore, we hypothesize the following:

Hypothesis 1: There will be a significant difference in terms of need for media richness between Western culturally-oriented managers (low uncertainty avoidance and low cultural context) and managers with a different cultural background (high uncertainty avoidance, and high cultural context in particular).

Furthermore, since new ICT are more integrated in the Western culture than in non-Western cultures, in this study we suggest that technological richness (i.e. the new form of richness associated with new ICT) will be more needed by western managers than others. We, therefore, propose:

Hypothesis 2: There will be a significant difference in terms of need for technological richness between Western managers and managers with a different cultural background.

Moreover, since the main cultural dimensions more likely to influence media use by individuals are uncertainty avoidance, power distance, collectivism and cultural context as pointed out in the literature review, we hypothesize that these cultural dimensions will influence users' needs for media richness and technological richness in the following way:

Hypothesis 3: High uncertainty avoidance, high power distance, high collectivist values, and high cultural context will lead to high need for media richness.

Hypothesis 4: Low uncertainty avoidance, low power distance, low collectivist values, and low cultural context will lead to high need for technological richness.

\section{METHODOLOGY}

Canada and China, two countries with different cultural profiles according to Hofstede ([23, [24]) and $\mathrm{Su}$ and Lessard [42], were selected to test the hypotheses. Based on survey instruments from previous studies, a questionnaire was developed in order to collect data about cultural dimensions at individual level (Dorfman and Howell [8]), need for media richness (Daft et al. [3]), and need for technological richness (Illia \& Roy [26]). All of the constructs were measured using 5-point Likert scales. In each case, multiple items were used to measure the construct. For the need for media richness and the need for technological richness constructs, the respondents were asked the extent to which different aspects of media richness and technological richness are necessary to achieve effective communication in ambiguous work situations (Daft et al [2]; ElShinnawy \& Markus [9]). The Appendix shows some sample questions asked to the respondents. A Chinese citizen with an extensive experience in translating research documents performed the translation of the English version of the questionnaire into Chinese (Mandarin). The first Chinese version of the questionnaire was reviewed by a Chinese professor at a major Canadian university. Prior to the use in the field, the questionnaire was pre-tested to refine constructs and measures using data from Chinese and Canadian graduate students. Then, a total of 2000 questionnaires were distributed to the Human Resources managers of Chinese and Canadian Bank \& Insurance organizations who previously agreed to participate in the study. The overall response rate is $32 \%$ in China and $30.5 \%$ in Canada. The data collected in the field was used to assess the reliability (i.e. internal consistency) and the validity (i.e. unidimensionality) of the measures using Cronbach alphas and confirmatory factor analysis with maximum likelihood (Gerbing \& Anderson [14]). Prior to the statistical tests, the Levene test showed that the Chinese and the Canadian groups of respondents have a similar distribution for the test variables $(\mathrm{p}<.05)$. An initial test showed that the two groups of respondents are statistically different for all cultural dimensions. Figure 1 shows a graphical view of the cultural differences.

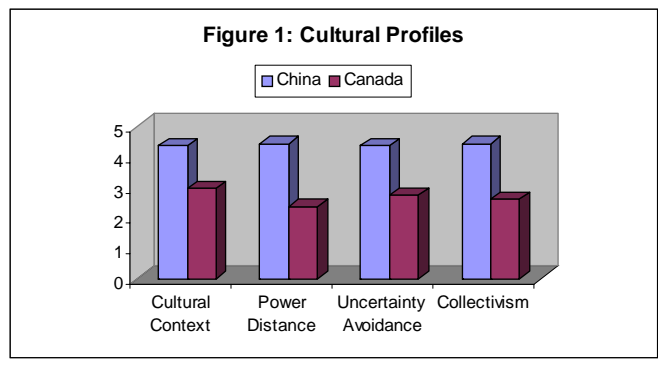


In order to assess the extent to which the Canadian respondents (low uncertainty avoidance and low cultural context) differ from the Chinese respondents (high uncertainty avoidance and high cultural context) in terms of which ICT characteristics they might prefer, variance analyses and means comparison tests were performed. Table 1 shows the results of the equality of means' tests. Hypothesis 1 is supported because, as the results show, compared to Canadians, Chinese respondents showed more interest in communication media's capacity to allow for multiple cues ( $\mathrm{p}=.029)$, instant feedback ( $\mathrm{p}=.037$ ), personal focus $(p=.04)$ and use of variety of languages $(p=.042)$. This suggests that compared to Canadians, Chinese respondents might prefer communication media which design includes features that allow for multiple cues (audio and video features for instance), instant feedback, personal focus (capacity to tailor messages to the receivers' frame of reference, and needs), and language variety (range of meaning that can be conveyed with symbols for instance). As can be seen in Table 1, Hypothesis 2 is not statistically supported because there are no significant differences between Chinese and Canadian respondents in terms of the extent to which they are interested in the following technological richness aspects: capacity to store messages and data in general $(p=.130)$, capacity for easy retrieval of stored messages $(\mathrm{p}=.324)$, anytime-anywhere availability $(\mathrm{p}=.217)$, and synchronousness $(\mathrm{p}=.315)$. But, the relatively high mean values (Means) observed for all aspects of technological richness in both Canadian and Chinese samples are indications of a very high interest in technological richness by both groups of respondents.

Table 1: Equality of means' tests

\begin{tabular}{|c|c|c|c|c|c|c|c|c|c|}
\hline \multirow{2}{*}{\multicolumn{2}{|c|}{ Characteristics }} & \multicolumn{2}{|c|}{ Chinese } & \multicolumn{2}{|c|}{ Canadians } & \multirow{3}{*}{$\frac{\mathbf{t}}{2.189}$} & \multirow{3}{*}{$\begin{array}{c}\text { df } \\
610\end{array}$} & \multirow{3}{*}{$\begin{array}{c}\mathbf{p} \\
0.029\end{array}$} & \\
\hline & & Mean & S.D. & Mean & S.D. & & & & \multirow{5}{*}{ H1 } \\
\hline \multirow{4}{*}{ 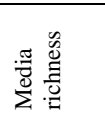 } & Need for multiple cues & 4.38 & 0.65 & 4.05 & 0.71 & & & & \\
\hline & Need for instant feedback & 4.37 & 0.57 & 3.12 & 0.67 & 2.090 & 610 & 0.037 & \\
\hline & Need for personal focus & 4.29 & 0.61 & 3.18 & 0.68 & 2.058 & 610 & 0.040 & \\
\hline & Need for language variety & 4.31 & 0.56 & 3.30 & 0.59 & 2.038 & 610 & 0.042 & \\
\hline \multirow{4}{*}{ 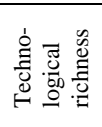 } & Need for storage capacity & 4.30 & 0.68 & 4.36 & 0.64 & 1.516 & 610 & 0.130 & \multirow{4}{*}{ H2 } \\
\hline & Need for message accessibility & 4.29 & 0.65 & 4.35 & 0.61 & 0.987 & 610 & 0.324 & \\
\hline & Need for anytime-anywhere availability & 4.28 & 0.67 & 4.30 & 0.60 & 1.236 & 610 & 0.217 & \\
\hline & Need for synchronousness & 4.25 & 0.59 & 4.31 & 0.56 & 1.006 & 610 & 0.315 & \\
\hline
\end{tabular}

In order to assess the extent to which there are relations between the cultural dimensions on the one hand, and the need for media richness and the need for technological richness on the other hand, the entire dataset was split in two datasets. As recommended by Ramanujam et al [33], two groups were created based on the median value of the multiitem 5-point scale used to measure the cultural dimensions constructs. The first group, referred to as Group 1 next, included all respondents with observed values of less than 3 for Uncertainty Avoidance,

Table 2: Means comparison tests

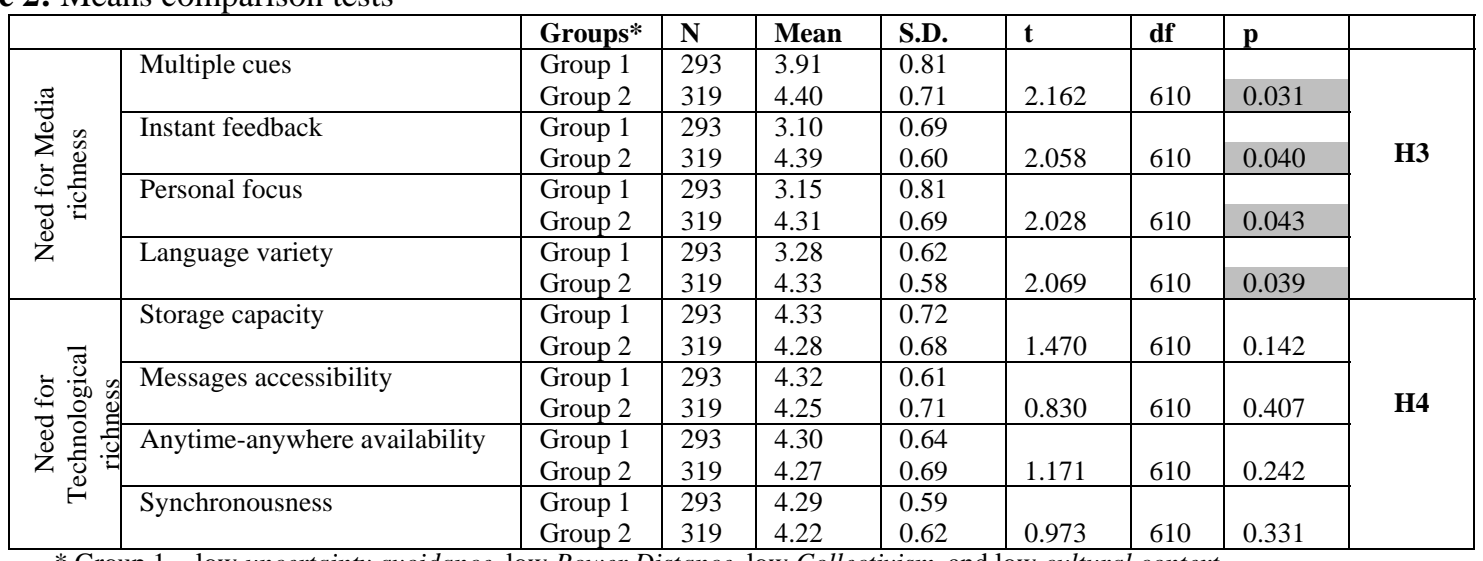

* Group 1 = low uncertainty avoidance, low Power Distance, low Collectivism, and low cultural context.
* Group 2 = high uncertainty avoidance, high power distance, high collectivism, and high cultural context.
Power Distance, Collectivism, and Cultural Context richness. The second group included all respondents with observed values of 3 or higher. Table 2 shows the results of the tests of means comparisons between the two groups. As the results show, Hypothesis 3 is supported because compared to Group 1's respondents, Group 2's respondents expressed more interest for media richness in terms of multiple cues $(\mathrm{p}=.031)$, instant feedback $(\mathrm{p}=.040)$, personal focus $(\mathrm{p}=.043)$ and language variety $(\mathrm{p}=.039)$. 
This implies that, as potential users, the respondents whose cultural profile is characterized by a high uncertainty avoidance, a high power distance, collectivist values, and a high cultural context might be more interested than their counterparts in communication technologies the design of which includes features that make them rich in terms of media richness. Results from Table 2 also show that Hypothesis 4 is not supported by the data at a $5 \%$ significance level because, compared to Group 2, Group 1's respondents did not express a significantly higher interest in any aspect of the technological richness ( $\mathrm{p}^{>} .05$ in all cases).

\section{DISCUSSION AND CONCLUSION}

The results of this study showed that there is a significant difference between the Chinese and Canadian workers involved in the research in terms of their interest in different aspects of media richness. The results also showed that there is a link between the respondents' interest in media richness and some cultural dimensions. Overall, the results of this study tell us two key things. First, because of cultural values like high uncertainty avoidance and high cultural context, communication partners might need more media richness-related features that could help them exchange verbal as well as non-verbal cues and have more effective communication in ambiguous work situations. This particular outcome could be explained, at least in part, by the theory of social presence. According to the theory of social presence, communication media differ in their ability to transmit information about communicators and communication's context. The theory states that media that convey cues like communicators' appearance, gender, age, mood, and so forth create a better sense of social presence that would make people prefer using them in ambiguous work situations. But what the results of this study (Hypothesis 3) further suggested is that the "sense of social presence" is not as much important for the Canadian group of respondents (low uncertainty avoidance and low cultural context) as it is for the Chinese group of respondents (high uncertainty avoidance and high cultural context values). Indeed the results showed that there is a significant difference between the two groups in terms of how much they like the ability to convey cues. In other words, what the theory of social presence stated as a general principle seems to have some cultural values as intervening factor. To some extent, the results also confirm some of the findings of Ook [32] who showed that, in Korea, the use of communication media is based on their capacity to convey cultural protocols (showing respect through multiple cues and personal focus for instance). These results suggest that global information and communication systems' designers might improve the likely acceptance of their products by trying to adapt their design to the cultural context of different target markets. This would mean including things like full-duplexity and audio-video features in communication systems designed for places where the culture is characterized by high Uncertainty Avoidance and high Cultural Context, which is consistent with Heaton [20] who found out that in Japan, a rich-context society, communication technologies' designers tend to use a lot of features that could help restore the communication context.

The other key thing that came out of the study is that the results also suggest that cultural values don't have any impact on the extent to which people are interested in ICT-related features like storage capacity, data accessibility, and Anytime-Anywhere availability because the data didn't support Hypothesis 2 and Hypothesis 4 which predicted that, given the fact that ICT are more integrated in the western culture than in non-western cultures, managers with western-oriented cultural values will be more interested in ICT-related features. There are several ways to explain this second outcome. One possible explanation is that even though ICT are more integrated in the western culture than in other cultures, people in non-western countries who are well exposed to ICT can discover their technological richness and find it good for them as suggested by Feldman \& Lynch's study [11] about the influence of experience and memory on attitude and behavior. In this case, all of the respondents are from the Banking and Insurance sector that widely uses communication media across countries. And the statistical analysis of the collected data about the respondents' access to ICT like email, the World Wide Web, and electronic board indicates a high level of access for the Chinese respondents (4.06 on a 5-point Likert scale in average) and the Canadian respondents (4.2 on a 5point Likert scale in average). Furthermore, it showed that there is no significant difference between the two groups of respondents in terms of access to those ICT in the workplace. This suggests that exposure to (and experience with) ICT might have played a role in the Chinese showing the same level of interest in ICTrelated features. This explanation is consistent with the study of Guriting and Ndubisi [15] and Lippert and Howard [29] that showed that experience with technologies has a significant influence on the way Malaysian users perceived online banking as a useful technology. On the other hand, the very high level of interest for technological richness observed in both Canadian and Chinese samples could be interpreted 
as a sign that both groups of respondents might be willing to use communication IT with high capacity to: store messages/information, allow easy retrievals of stored messages/information, make it possible for users to be reached anytime and anywhere, and provide some kind of acknowledgment system, which could be achieved through using connection-oriented communication protocols like Transmission Control Protocol (TCP).

But, due to the complex nature of the culture concept, future research addressing the same issue using the cultural dimensions measures in similar contexts is needed before claims about generality can be made conclusively.

\section{REFERENCES}

1. Culnan M. J. \& Markus L. M. Information technologies, in Jablin Frederick, Putman Linda L. Roberts Karlene H. \& Poter Lyman W. (eds), Handbook of Organizational Communication: An Interdisciplinary Perspective, Sage Publications, 1987.

2. Daft R. L. and Lengel R. H. Organizational Information Requirements, Media Richness and Structural Design », Management Science, 32 (5), 1986, 554-571

3. Daft R. L., Lengel R. H. and Trevino L.K. The relationship among message equivocality, media selection, and manager performance, MISQ 11(3), 1987, 355-366

4. Daft R.L. \& Lengel R.H. Information Richness: A new approach to managerial behavior and organization design, Research in Organizational Behavior, Vol. 6, 1984, 191-233.

5. Davis Fred D. A Technology Acceptance Model For Empirically Testing New End-User Information Systems: Theory and Results doctoral dissertation, MIT Sloan School of Management, 1986, Cambridge, MA.

6. Davis Fred D. User acceptance of IT: System characteristics, user perceptions and behavioral impacts, International Journal of Man-Machine Studies, 38, 1993, 475-487.

7. Davis Fred D. Perceived usefulness, Perceived ease of use, and User Acceptance of Information technology, MIS Quarterly, 13(3), 1989, 319339.

8. Dorfman Peter W. \& Howell Jon P. Dimensions of National Culture and Effective Leadership Patterns: Hofstede Revisited; Advances in International Comparative Management, Vol. 3, 1988, 127-150.
9. El-Shinnawy Maha \& Markus Lynne M. Acceptance of Communication Media in Organizations: Richness or Features?, IEEE Transactions on Professional Communication, 41 (4), 1998, 242-253.

10. El-Shinnawy Maha M. \& Markus Lynne. Media Richness Theory and New Electronic Communication Media: A Study of Voice Mail and Electronic Mail, Proceedings of the thirteenth ICIS, 1992, 91-105. Dallas Texas.

11. Feldman Jack M. \& Lynch John G. SelfGenerated Validity \& Other Effects of Measurement on Belief, Attitude, Intention, and Behavior, Journal of Applied Psychology, 73(3), 1988, 421-435.

12. Filipczak Bob. The Ripple Effect Of Computer Networking. Training 31(3), March 1994

13. Fulk J., Steinfield C. W., Schmitz J. J. \& Power G. J. A social information Processing model of media use in organizations, Communication Research, 14, 1987, 520-552.

14. Gerbing D. W. \& Anderson J. C. An updated paradigm for scale development incorporating unidimentionality and its assessment, Journal of Marketing Research, Vol. 25, , 1988, 186-192.

15. Guriting Petrus and Ndubisi Nelson O.. Borneo Online Banking: Evaluating Customers Perceptions and Behavioral Intention. Management Research News, 29(1), 2006, 6-15.

16. Guide Quebec Inc. Guide d'information d'affaires du Quebec, InfoSearch Inc.., 2000, Montreal, Canada.

17. Hall Edward T. The Hidden Dimensions, Anchor Books, 1966 and 1982, Doubleday, N Y.

18. Hall Edward T. Au-delà de la culture, Éditions du seuil, 1976 and 1979, Paris.

19. Hasan Helen \& Ditsa George, The impact of culture on the adoption of IT: An interpretive study, Journal of Global Information Management, 7(1), 1999. 5-15.

20. Heaton Lorna. Preserving Communication Context: Virtual Workplace and Interpersonal Space in Japanese CSCW, in Ess Charles \& Sudweeks Fay (eds) "Cultural attitudes towards technology and communication", Sydney, Australia, 1998, 163-186.

21. Herbig P. A. The innovation matrix: Culture \& Structure Prerequistes to Innovation, Quorum Books, 1994), Westport, CT.

22. Ho T. H., Raman K. S., \& Watson R. T., Group Decision Support Systems : The Cultural Factor, Proceedings of the $10^{\text {th }}$ Annual ICIS, Boston, 1989, 119-129.

23. Hofstede Geert. Culture and Organizations, McGraw Hill., 1991. 
24. Hofstede Geert. Culture's Consequences, Sage, 1980.

25. Hofstede Geert. Vivre dans un monde multiculturel, Comprendre nos programmations mentales, Les éditions d'organisation, Paris, 1994.

26. Illia Abdou \& Roy Marie Christine. Traditional Media and New IT: Investigating Their Media Richness versus Their Technological Richness. Academy of Information and Management Sciences Journal. Volume 4, Number 2, 2001, 79-92.

27. Lengel Robert H. and Daft Richard L. The Selection of Communication Media as an Executive Skill, The Academy of Mgtt Executive, 11(3), 1988, 225-232

28. Limaye Mohan R. and Victor David A. Crosscultural Business Communications Research: State of the Art and Hypotheses for the 1990s. The Journal of Business Communication, 28(3), 1991, 277-299.

29. Lippert Susan and Howard Forman. Utilization of Information Technology: Examining Cognitive and Experiential Factors of PostAdoption Behavior. IEEE Transactions on Engineering Management, 52(3), 2005, 363-381.

30. Markus Lynne. Electronic Mail as the medium of managerial choice, Organization Science, 5(4), 1994, 503-527.

31. Nunnaly J. C. Psychometric Theory, 2nd Edition, McGraw-Hill, 1978, New York. 32. Ook Lee, The role of cultural protocol in media choice in a Confucian virtual workplace, IEEE Trans on Professional Communication, 44 (2), 2000, 196-200.

32. Ramanujam V., Venkatraman N. and Camillus J. C. Multi-Objective Assessment of Effectiveness of Strategic Planning: A Discriminant Analysis Approach, Academy of Management Journal, 29:2, 1986, 347-372.

33. Rice Ronald E. Task Analyzability, Use of New Media, and Effectiveness: A multi-site exploration of media richness, Organization Science, 3 (4), 1992, 475-500.
34. Rice Ronald E. Media Appropriateness: Using Social Presence Theory to compare traditional and new organizational media, Human Communication Research, 19 (4), 1993, 451484.

35. Rogers Everett M. Diffusion of innovations, $4^{\text {th }}$ edition, The Free Press, 1995, New York, 519p.

36. Sagi et al. ICT and Business in the New Economy: Globalization and Attitudes towards eCommerce, Journal of Global Information Mgt, 12:3, 2004, 44-64.

37. Shore B. and Vankatachalam A. Role of national culture in the transfer of information technology, Journal of Strategic Information Systems, 5:1, 1996, 19-35.

38. Straub Detmar. The effect of culture on IT diffusion: E-mail and fax in Japan and the U.S, ISR 5(1), 1994, 23-47

39. Straub Detmar, Keil Mark \& Brenner Walter. Testing the technology acceptance model across cultures: A three country study, Information \& Management, 33(1), 1997, 1-11.

1. 41. Straub Detmar. Validating Instruments in MIS Research, MIS Quarterly 13 (2), 1989, 147-169

2. 42. Su Zhan and Lessard Louis-Frédéric. Application d'un modèle révisé de Hofstede à la compréhension des traits culturels des gestionnaires québécois, Revue Organisation, No $1,1998$.

3. 43. Suh Kil Soo, Impact of communication medium on task performance and satisfaction: An examination of media richness theory, Information \& Management 35(5), 1999, 295312.

4. 45. Trevino L. K.; Lengel R. H.; Bodensteiner W.; Gerloff E. \& Muir N. K. The richness imperative and cognitive style: The role of individual differences in media choice behavior, Management Communication Quarterly, 4 (2), 1990, 176-197

5. 46. Viega John F, Floyd Steven, and Dechant Kathleen. Towards modeling the effect of national culture on IT implementation and acceptance. Journal of Information Technology, 16, 2001, 145-158. 


\section{Appendix A: Sample of questions included in the survey instrument}

\section{Sample questions for measuring cultural dimensions (Adapted from Dorfman \& Howell 1988)}

In the questionnaire below, please indicate the extent to which you agree or disagree with each statement. For example, if you strongly agree with a particular statement, you would circle the number $\underline{5}$ next to that statement.

\begin{tabular}{|c|c|c|c|}
\hline $\begin{array}{l}\text { Strongly } \\
\text { disagree }\end{array}$ & & & \\
\hline 1 & 2 & 3 & 4 \\
\hline 1 & 2 & 3 & 4 \\
\hline 1 & 2 & 3 & 4 \\
\hline 1 & 2 & 3 & 4 \\
\hline 1 & 2 & 3 & 4 \\
\hline 1 & 2 & 3 & 4 \\
\hline 1 & 2 & 3 & 4 \\
\hline 1 & 2 & 3 & 4 \\
\hline 1 & 2 & 3 & 4 \\
\hline 1 & 2 & 3 & 4 \\
\hline 1 & 2 & 3 & 4 \\
\hline 1 & 2 & 3 & 4 \\
\hline 1 & 2 & 3 & 4 \\
\hline 1 & 2 & 3 & 4 \\
\hline
\end{tabular}
employees.

Note (not included in the questionnaire): Items 1 through 4 are used to measure Uncertainty Avoidance; items 5 through 9 are used to measure Collectivism, and items 10 through 14 are used to measure Power Distance.

\section{Sample questions for measuring the need for media richness}

In the questionnaire below, please indicate the extent to which you agree or disagree with each statement in the following work situations. For example, if you strongly agree with a particular statement, you would circle the number $\underline{5}$ next to that statement.

Work situation 1: You need to use a communication medium in order to get clarification of an ambiguous directive from your colleague.

Strongly Strongly disagree agree

1. It's important that the communication medium can convey cues like voice inflection and mood.

$\begin{array}{lllll}1 & 2 & 3 & 4 & 5\end{array}$


2. It is important that the communication medium can convey cues like gesture and body language.

3. Is it important that the communication medium provides a mean to be aware of the communication context in which my communication partner is (daytime, weather, etc).

4. It is important that the communication medium allows me to get instant feedback from my communication partner.

5. It is important that the communication medium allows having communications where my words and my language are tailored to the person I am dealing with.

5. It is important that the communication medium allows using a variety of languages including sign language.

6. It is important that the communication medium allows using a variety of languages including symbols and graphics. $\begin{array}{lllll}1 & 2 & 3 & 4 & 5\end{array}$

$\begin{array}{lllll}1 & 2 & 3 & 4 & 5\end{array}$

$\begin{array}{lllll}1 & 2 & 3 & 4 & 5\end{array}$

$\begin{array}{lllll}1 & 2 & 3 & 4 & 5\end{array}$

$\begin{array}{lllll}1 & 2 & 3 & 4 & 5\end{array}$

$\begin{array}{lllll}1 & 2 & 3 & 4 & 5\end{array}$ 